\title{
Penerapan Metode Promethee Dalam Sistem Pendukung Keputusan Penetapan Penerima Kartu Indonesia Sehat (KIS)
}

\author{
Reva Octaviani Siregar ${ }^{*}$, Deci Irmayani, Masrizal \\ Manajemen Informatika, Universitas Labuhan Batu, Rantauprapat, Indonesia \\ Email: 1," revadira13@gmail.com, ${ }^{2}$ deacyirmayani@gmail.com, ${ }^{3}$ masrizal120405@gmail.com \\ Email Penulis Korespondensi: revadira13@gmail.com
}

\begin{abstract}
Abstrak-Kesehatan merupakan keadaan sejahtera dari badan, jiwa dan sosial yang memungkinkan setiap orang hidup produktif secara sosial dan ekonomi. Karena itu, kesehatan adalah unsur yang paling penting dalam hidup manusia. Kesehatan sangat erat dengan kondisi ekonomi. faktor-fakor yang mempengaruhi kesehatan manusia seperti makanan dan minuman yang sehat, lingkungan yang sehat dan kebiasaan hidup dengan sehat akan terpenuhi. Sebaliknya jika ekonomi yang buruk akan menyulitkan individu masyarakat untuk memenuhi beberapa faktor tersebut, di mana jika kondisi tersebut diabaikan maka individu masyarakat akan kesulitan memperbaiki kesehatan mereka masing-masing. Permasalahan yang terjadi di Puskesmas Galang adalah pemilihan peserta KIS (Kartu Indonesia Sehat) yang kurang memuaskan. pemilihan peserta KIS (Kartu Indonesia Sehat) memerlukan sistem pendukung keputusan (SPK) untuk mempercepat dan mempermudah dalam membuat suatu keputusan. Sistem pendukung keputusan digunakan untuk membantu pengambilan keputusan dalam sebuah organisasi untuk mempermudah dalam pengambilan sebuah keputusan. Di mana tidak seorang pun mengetahui secara pasti bagaimana seharusnya keputusan di buat. Metode Promethee (Preference Ranking Organizational Method for Enrichment Evaluation) merupakan metode yang digunakan untuk penentuan prioritas (urutan) dalam analisis multi kriteria. Dengan metode Promethee permasalahan tentang pemilihan peserta KIS (Kartu Indonesia Sehat) layak digunakan dalam penelitian ini, metode penelitian yang dilakukan dalam penelitian ini adalah dimulai dari pengumpulan data, analisis masalah, analisa metode, perancangan dan pengujian aplikasi yang akan dibangun, tujuan penelitian ini dilakukan untuk mengatasi permasalahan para peserta KIS (Kartu Indonesia Sehat) yang selama ini kurang puas dalam hal keputusan penerima KIS (Kartu Indonesia Sehat).hasil penelitian yang didapat bahwa dari tiga peserta KIS (Kartu Indonesia Sehat) yang di uji didapatkan dua orang peserta yang layak mendapatkan KIS (Kartu Indonesia Sehat) berdasarkan hasil penilaian lima kriteria yang digunakan sehingga didapatkan hasil perhitungan dengan metode Promethee bahwa nilai net flow dari masing-masing alternatef adalah -1 untuk alternative 1 dan 0,2 untuk alternative 2 dan 0,8 untuk altenatif ketiga.
\end{abstract}

Kata Kunci: Kesehatan; Kartu Indonesia Sehat; Sistem Pendukung Keputusan; Metode Promethee

\begin{abstract}
Health is a state of well-being of body, soul and society that enables everyone to live productively socially and economically. Therefore, health is the most important element in human life. Health is closely related to economic conditions . factors that affect human health such as healthy food and drinks, a healthy environment and healthy living habits will be fulfilled. Conversely, if a bad economy will make it difficult for individual people to meet some of these factors, if these conditions are ignored, the individual community will find it difficult to improve their health. The problem that occurred at Galang Health Center was the unsatisfactory selection of KIS (Kartu Indonesia Sehat) participants. the selection of KIS (Kartu Indonesia Sehat) participants requires a decision support system (DSS) to speed up and make it easier to make decisions. Decision support systems are used to assist decision making in an organization to facilitate decision making. Where no one knows exactly how decisions should be made. The Promethee method (Preference Ranking Organizational Method for Enrichment Evaluation) is a method used to determine priority (order) in multi-criteria analysis. With the Promethee method, the problem of choosing KIS (Kartu Indonesia Sehat) participants is feasible to use in this study, the stages of research carried out in this study are starting from data collection, problem analysis, method analysis, design and testing of applications to be built, the purpose of this research is to solve the problems of the participants. KIS (Kartu Indonesia Sehat), which have been unsatisfied in terms of the decision of KIS (Kartu Indonesia Sehat) recipients. The results showed that of the three KIS (Kartu Indonesia Sehat) participants who were tested, there were two participants who deserved KIS (Kartu Indonesia Sehat) based on the results of the assessment of the five criteria used so that the calculation results using the Promethee method showed that the net flow from each of the alternatef is -1 for alternative 1 and 0.2 for alternative 2 and 0.8 for the third alternative.
\end{abstract}

Keywords: Health; Healthy Indonesia Card; Decision Support Systems; Promethee Method

\section{PENDAHULUAN}

Menurut [1] Kesehatan merupakan keadaan sejahtera dari badan, jiwa dan sosial yang memungkinkan setiap orang hidup produktif secara sosial dan ekonomi. Karena itu, kesehatan adalah unsur yang paling penting dalam hidup manusia. Kesehatan sangat erat dengan kondisi ekonomi. faktor-fakor yang mempengaruhi kesehatan manusia seperti makanan dan minuman yang sehat, lingkungan yang sehat dan kebiasaan hidup dengan sehat akan terpenuhi. Sebaliknya jika ekonomi yang buruk akan menyulitkan individu masyarakat untuk memenuhi beberapa faktor tersebut, di mana jika kondisi tersebut diabaikan maka individu masyarakat akan kesulitan memperbaiki kesehatan mereka masing-masing

Menurut Dinas Kesehatan tahun 2005 Jaminan Kesehatan masyarakat adalah program bantuan sosial pelayanan kesehatan bagi masyarakat miskin dan tidak mampu. Program ini diselenggarakan secara nasional agar terjadi subsidi silang dalam rangka mewujudkan pelayanan kesehatan yang menyeluruh bagi masyarakat miskin. Penyelenggara pelayanan kesehatan yang semakin kompleks menunutut penangan professional yang mampu mengatasi suatu masalah dalam pemilihan penerima KIS (Kartu Indonesia Sehat) bagi masyarakat. Karena saat 
ini banyak KIS (Kartu Indonesia Sehat) yang dinilai tidak tepat sasaran, di mana masih banyak orang yang seharusnya berhak, justru tidak mendapat dana bantuan tersebut. Di sebabkan oleh banyaknya peserta KIS (Kartu Indonesia Sehat) dan ketidakakuratan dalam menghitung atau menilai kriteria peserta KIS (Kartu Indonesia Sehat).

Permasalahan yang terjadi di Puskesmas Labuhan Batu adalah pemilihan peserta KIS (Kartu Indonesia Sehat) yang kurang memuaskan. pemilihan peserta KIS (Kartu Indonesia Sehat) memerlukan sistem pendukung keputusan (SPK) untuk mempercepat dan mempermudah dalam membuat suatu keputusan. Sistem pendukung keputusan digunakan untuk membantu pengambilan keputusan dalam sebuah organisasi untuk mempermudah dalam pengambilan sebuah keputusan. Di mana tidak seorang pun mengetahui secara pasti bagaimana seharusnya keputusan di buat. Salah satu metode yang digunakan pada sistem pendukung keputusan ini adalah Metode Promethee (Preference Ranking Organizational Method for Enrichment Evaluation)

Menurut jurnal [2] berjudul "Sistem Pendukung Keputusan Menggunakan Metode Promethee (Studi Kasus : Stasiun Pengisian Bahan Bakar Umum)" Metode Promethee merupakan salah satu metode dari beberapa metode yang digunakan dalam pengambilan suatu keputusan. Untuk menggunakan sistem pendukung keputusan harus memliki kriteria-kriteria yang akan digunakandalam penentuan pemilihan, selain itu harus menentukan tingkat kepentingan dari tiap-tiap kiteria. Dalam penelitian [3] metode promethee memerlukan proses perkalian multi kriteria. Hasil perkalian tersebut belum bermakna jika belum dibandingkan (dibagi) dengan nilai standart. Bobot untuk atribut bermanfaat berfungsi sebagai pangkat positif dalam proses perkalian, sementara bobot biaya berfungsi sebagai pangkat negatif. Penelitian [4] menguraikan bahwa dengan metode prometthee dapat menyelesaikan permasalahan pada kasus pemeringkatan mahasiswa, dalam peneltiain tersebut didapatkan hasil nilai tertinggi sebesar 0,739 untuk alternatif A16. Dari beberapa peneltiian diatas dapat ditunjukkan bahwa sangat penting dilakukan penelitian dengan metode Promethee yang layak untuk pendukung keputusan penetapan penerima KIS (Kartu Indonesia Sehat).

\section{METODOLOGI PENELITIAN}

\subsection{Tahapan Penelitian}

Dalam menyelesaikan penelitian ini melakukan penelitian dengan metode meneliti berdasarkan fakta-fakta, objek dan juga permasalahan dan kebutuhan yang sudah dikumpulkan selanjutnya dianalis dengan tujuan menghasilkan suatu kesimpulan dari deskripsi yang secara sistematis. Tahapan peneltian dapat dilihat pada gambar 1 .

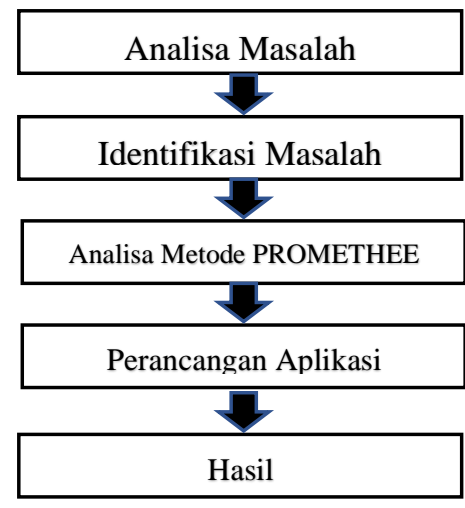

Gambar 1. Tahapan Penelitian

Dari tahapan penelitian diatas dapat dijelaskan bahwa:

1. Analisa Masalah

Tahapan ini dilakukan untuk menganalisa akar permasalah yang terjadi dalam penetapan kelayakan penerima KIS (Kartu Indonesia Sehat) pada puskesmas labuhan Batu serta menganalisa bagaimana proses pemberian Jaskesmas tersebut.

2. Identifikasi Masalah

Tahapan identifikasi dilakukan mengumpulkan berbagai identifikasi masalah mengapa permasalahan dalam pemberian KIS (Kartu Indonesia Sehat) dapat terjadi tidak sesuai dengan yang diharapkan masyarakat.

3. Analisa Metode Promethee

Dalam tahapan ini peneliti melakukan penganalisaan metode dengan menggunakan data-data yang didapatkan langsung dari tempat penelitian dengan melakukan wawacara langsung dengan masyarakat di daerah Labuan Batu, selanjutnya menyelesaikan dengan mengikuti tahapan-tahapan yang ada pada Metode Promethee

4. Perancangan Aplikasi 
Tahapan ini peneliti merancang aplikasi yang didalamnya sudah menerapkan satu metode dalam memecahkan permasalahan tentang penerima serta menguci aplikasi yang dibuat sesuai dengan kebutuhan desa untuk mengetahui kekurangan dan error dari aplikasi yang dibuat

5. Hasil

Menyimpulkan dari hasil penelitian yang dilakukan untuk megetahui tingkat keberhasilan dari aplikasi yang sudah di uji yang didalamnya sudah terujia satu metode pendukung keputusan.

\subsection{Sistem Pendukung Keputusan}

Menurut [5] sistem pendukung keputusan Pengambilan keputusan adalah suatu proses pemikiran dalam rangka pemecahan suatu masalah untuk memperoleh hasil akhir untuk dilaksanakan. Masalah berbeda dengan persoalan, meskipun keduanya merupakan pertayaan untuk dijawab. Penelitian [6] juga mengutarakan bahwa Suatu organisasi dalam melakukan pengambilan keputusan merupakan hasil komunikasi yang melibatkan seluruh organisasi

\subsection{Metode PROMETHEE}

Metode Promethee (Preference Ranking Organizational Method for Enrichment Evaluation) merupakan salah satu metode yang proses pengerjaanya secara multikriteria[7][8]. Dengan metode ini dapat diterapkan dalam menentukan keputusan yang terbaik melalui tahapan penilaian dari setiap kriteria dengan mengurutkan nilai prioritas didalam analisa perhitungan multikriteria.

Metode Promethee dikategorikan juga kedalam metode pendekatan dalam outranking(peringkatan) dengan ketetapan nilai prioritas alternative berdasarkan persamaan (1).

$\operatorname{Max}\{f 1(x), f 2(x), f 3(x), \ldots . f i(x) L x € A$

Keterangan:

1. A kumpulan dari alternative pilihan yang terjadi, [9][10]

2. $f_{1}, f_{2} \ldots f_{k}$ kriteria yang dievaluasi sebelumnya.

Langkah-langkah metode Prometehee:

1. Menentukan nilai alternative dari data dengan cara memilih kriteria-kriteria (dominasi kriteria) yang digunakan dalam pemilihan system pendukung keputusan [11][12].

2. Menentukan fungsi prefensi dan nilai prefensi

3. Pemeringkatan Promethee, dengan menghitung arah preferensi yang dipertimbangkan berdasarkan nilai indeks preferensi, leaving low, entering flow, dan net flow [13][14] .

4. Menentukan tipe preferensi untuk setiap kriteria yang paling cocok didasarkan pada data dan pertimbangan dari decision maker. Tipe preferensi ini berjumlah Enam (Usual, Quasi, Linear, Level, Linear Quasi dan Gaussian)[15][15]

5. Memberikan nilai threshold atau kecenderungan untuk setiap kriteria berdasarkan preferensi yang telah dipilih.

6. Perhitungan Entering flow, Leaving flow dan Net flow.

7. Hasil pengurutan hasil dari perangkingan [16] [17].

\section{HASIL DAN PEMBAHASAN}

Untuk mengetahui hasil penilaian untuk kelayakan pemberian KIS (Kartu Indonesia Sehat) pada Puskesmas Labuhan Batu dibutuhkan beberapa kriteria dan alternative yang akan digunakan dalam perhitungan metode Promethee. Adapun yang mejadi kriteria yang digunakan adalah sebagai berikut :

Tabel 1. Kriteria

\begin{tabular}{|c|c|}
\hline Kode & Nama Kriteria \\
\hline K1 & Warga Kelurahan \\
\hline $\mathrm{K} 2$ & Pekerjaan \\
\hline K3 & Pendapatan \\
\hline K4 & Jenis Lantai Rumah \\
\hline K5 & Jenis Dinding Rumah \\
\hline
\end{tabular}

Selanjutnya mengetahui sub kriteria dan nilai bobot dari setiap kriteria, dapat dilihat pada tabel 2 berikut:

Tabel 2. Sub Kriteria Warga Kelurahan

\begin{tabular}{lc}
\hline Sub Kriteria & Bobot \\
\hline >10 Tahun & 5 \\
9-10 Tahun & 4 \\
6-8 Tahun & 3 \\
\hline
\end{tabular}




\begin{tabular}{ll}
\hline $2-5$ Tahun & 2 \\
1 Tahun & 1 \\
\hline
\end{tabular}

Tabel 3. Sub Kriteria Pekerjaan

\begin{tabular}{lc}
\hline Sub Kriteria & Bobot \\
\hline Karyawan Tetap & 5 \\
Wiraswasta & 4 \\
Petani & 3 \\
Tukang Becak & 2 \\
Kerja Harian & 1 \\
\hline
\end{tabular}

Tabel 4. Sub Kriteria Pendapatan

\begin{tabular}{lc}
\hline Sub Kriteria & Bobot \\
\hline$>1.200000$ & 3 \\
Rp. $600.000-1.200000$ & 2 \\
<Rp. 600.000 & 1 \\
\hline
\end{tabular}

Tabel 5. Sub Kriteria Dinding Rumah

\begin{tabular}{lc}
\hline Sub Kriteria & Bobot \\
\hline Fisik Dinding Rumah Terbuat dari Tepas & 1 \\
Fisik Dinding Rumah Terbuat dari Papan & 2 \\
Dingding Bangunan Permanen/Tembok Batu & 3 \\
Dinding Bangunan Tergolong Mewah Luas & 4 \\
\hline
\end{tabular}

Tabel 6. Sub Kriteria Lantai Rumah

\begin{tabular}{lc}
\hline Sub Kriteria & Bobot \\
\hline Lantai Rumah Keramik & 3 \\
Lantai Rumah Semen & 2 \\
Lanta Rumah Tanah & 1 \\
\hline
\end{tabular}

Didapatkan nilai dari setiap alternative terhadap sub kriteria berdasarkan hasil pengumpulan data yang dilakukan sebagai berikut :

Langkah 1: Menentukan nilai alternatif dari data dengan cara memilih kriteria-kriteria (dominasi kriteria) yang digunakan dalam pemilihan system pendukung keputusan.

Untuk alternatif A:

Kriteria $1=$ Warga Kelurahan masih 1 Tahun nilai bobot (1)

Kriteria 2= Pekerjaan Harian, Nilai Bobot (1)

Kriteria 3= Pendapatan $<$ Rp. 600.000, Nilai Bobot (1)

Kriteria 4= Jenis Lantai Rumah Tanah, Nilai Bobot (1)

Kriteria 5 = Jenis dinding Rumah terbuata dari tepas, nilai bobot (1)

Demikian seterusnya hingga didapat nilai dari alternatif B dan C, seperti terdapat pada tabel berikut:

Tabel 7. Penilaian

\begin{tabular}{cccc}
\hline \multirow{2}{*}{ Kriteria } & \multicolumn{3}{c}{ Nilai Calon Alternatif } \\
\cline { 2 - 4 } & A & B & C \\
\hline K1 & 1 & 5 & 5 \\
K2 & 1 & 4 & 4 \\
K3 & 1 & 2 & 3 \\
K4 & 1 & 3 & 4 \\
K5 & 1 & 2 & 3 \\
\hline
\end{tabular}

Tabel diatas merupakan Nilai yang didapatkan berdasarkan dari hasil pengumpulan data yang dilakukan yang selanjutnya disesuaikan dengan sub kriteria yang sudah ditetapkan.

Langkah 2: Menentukan fungsi prefensi dan nilai prefensi.

Setelah ditemukan nilai dari setiap alternative, selanjutnya dilakukan perhitungan mencari nilai presensi kritera denga ketentuan mengurangi nilai dari setiap alternative. Dapat dilihat pada tabel berikut. 


\section{JURNAL MEDIA INFORMATIKA BUDIDARMA}

Volume 5, Nomor 2, April 2021, Page 739-745

ISSN 2614-5278 (media cetak), ISSN 2548-8368 (media online)

Available Online at https://ejurnal.stmik-budidarma.ac.id/index.php/mib

DOI 10.30865/mib.v5i2.2948

Sebelum tahap perhitungan dilakukan, ditentukan terlebih dahulu tipe preferensi yang digunakan pada setiap kriteria, pada penelitian yang dilakukan persamaan yang dibuat adalah bernilai Negatif (-) dan Positif (+) pada metode promethee.

Dengan persamaan yang sudah ditetapkan maka dilakukan perhitungan nilai preferensi dengan cara membandikan pada setiap alternatif.

Nilai Alternatif A dikurangkan dengan Nilai Alternatif

(Alternatif $\mathrm{A}-$ Alternatif $\mathrm{B})=1-5=-4$

(Alternatif A- Alternatif C) $=1-5=-4$

Demikian seterusnya sampai (Alterntif C-Alternatif B) sehingga dapat ditemukan nilai presensi dari setiap alternatif pada tabel berikut

Tabel 8. Nilai Presensi Kriteria terhadap Alternatif (a,b)

\begin{tabular}{ccc}
\hline \multirow{2}{*}{ Kriteria } & \multicolumn{2}{c}{$(\mathbf{a}, \mathbf{b})$} \\
\cline { 2 - 3 } & $\mathbf{x}$ & $\mathbf{p}(\mathbf{x})$ \\
\hline K1 & -4 & 0 \\
K2 & -3 & 0 \\
K3 & -1 & 0 \\
K4 & -2 & 0 \\
K5 & -1 & 0 \\
\hline
\end{tabular}

Tabel 9. Nilai Presensi Kriteria terhadap Alternatif (a,c)

\begin{tabular}{cc}
\hline $\mathbf{x}$ & $\mathbf{( a , c )}$ \\
& $\mathbf{p}(\mathbf{x})$ \\
\hline-4 & 0 \\
-3 & 0 \\
-2 & 0 \\
-3 & 0 \\
-2 & 0 \\
\hline
\end{tabular}

Nilai $\mathrm{p}(\mathrm{x})$ didapatkan dengan ketentuan:

Jika nilai $\mathrm{x}$ bernilai negatif maka diberikan nilai $\mathrm{p}(\mathrm{x})=0$ sebaliknya jika nilai $\mathrm{x}$ bernilai positif diberikan nilai $\mathrm{p}(\mathrm{x})=1$.

Dari hasil perhitungan yang dilakukan didapatkan hasil index preferensi Multikriteria sebagai berikut.

Tabel 10. Nilai Index Preferensi Multikriteria

\begin{tabular}{cccc}
\hline & $\mathbf{a}$ & $\mathbf{b}$ & $\mathbf{c}$ \\
\hline $\mathbf{a}$ & & 0,0 & 0,0 \\
$\mathbf{b}$ & 1,0 & & 0,0 \\
$\mathbf{c}$ & 1,0 & 0,6 & \\
\hline
\end{tabular}

Langkah 3: Pemeringkatan Promethee, dengan menghitung arah preferensi yang dipertimbangkan berdasarkan nilai indeks preferensi, leaving low, entering flow, dan net flow

Untuk mendapatkan nilai leaving low berdasarkan indek preferensi adalah :

Alternatif $\mathrm{I}=1 /(3-1)(0,0+0,0)=0$

Alternatif II $=1 /(3-1)(1,0+0,0)=0,5$

Alternatif III $=1 /(3-1)(1,0+0,6)=0,8$

Dari hasil perhitungan dengan metode Promethee didapatkan hasil untuk calon penerima KIS (Kartu Indonesia Sehat)

Tabel 11. Nilai Promethee Ranking

\begin{tabular}{|c|c|c|c|}
\hline Alternatif & Leaving Flow & $\begin{array}{l}\text { Entering } \\
\text { Flow }\end{array}$ & $\begin{array}{l}\text { Net } \\
\text { Flow }\end{array}$ \\
\hline Alternatif A & 0 & 1 & -1 \\
\hline Alternatif B & 0,5 & 0,3 & 0,2 \\
\hline Alternatif C & 0,8 & 0 & 0,8 \\
\hline
\end{tabular}

Setelah didapatkan nilai leaving, entering, dan net flow maka selanjutnya tahap perangkingan dari leaving,entering, dan net flow seperti yang terlihat pada tabel 12 . 
Tabel 12. Perangkingan

\begin{tabular}{ccccc}
\hline Alternatif & Leaving Flow & $\begin{array}{l}\text { Entering } \\
\text { Flow }\end{array}$ & $\begin{array}{l}\text { Net } \\
\text { Flow }\end{array}$ & Rangking \\
\hline Alternatif A & 0 & 1 & -1 & 3 \\
Alternatif B & 0,5 & 0,3 & 0,2 & 2 \\
Alternatif C & 0,8 & 0 & 0,8 & 1 \\
\hline
\end{tabular}

Dari hasil perhitungan yang dilakukan dengan mengikuti langkah-langkah yang ada pada metode PROMETHEE makan didapatkan hasil bahwa Alernatif B dan Alternatif C Layak mendapatkan nilai 0,2 untuk nilai Alternatif $\mathrm{C}$ dan 0,8 Alternatif ketiga sebagai kriteria yang layak untuk mendapatkan KIS (Kartu Indonesia Sehat) pada Puskesma Labuhan Batu.

\section{KESIMPULAN}

Berdasarkan hasil dari penelitian yang lakukan mengenai proses pendukung keputusan pemilihan peserta KIS (Kartu Indonesia Sehat) yang telah diteliti mendapatkan hasil dari perhitungan berdasarkan kriteria dan alternative dari proses multikriteria dengan metode Promethee, dari perhitungan yang dilakukan dapat disimpulkan bahwa metode Promethee dapat menangani masalah pada Kasus Pemberian KIS (Kartu Indonesia Sehat) juga ditemukan kelebihan dari penelitian yang didapatkan pada penelitian adalah menemukan hasil yang akurat untuk setiap kelayakan yang ditetapkan untuk penerima KIS (Kartu Indonesia Sehat) pada Puskesmas Labuhan Batu, nilai yang didapat tergantung terhadap nilai altenatif untuk mendapatkan nilai Leaving Flow, Entering Flow dan Net Flow. Bagi penelitian berikutnya, kriteria dan alternatif supaya ditambah, sehingga data yang dimasukkan lebih bervariasi dan hasil yang didapatkan lebih jauh keakuratannya.

\section{UCAPAN TERIMAKASIH}

Penulis mengucapkan terima kasih kepada tim peneliti dan teman-teman dosen di universitas Labuhan Batu yang selalu memberi masukan dan ide-ide dalam penelitian ini, demikian juga terucap buat ketua LPPM Universitas Labuhan Batu atas dukungan kepada peneliti selama menyelesaikan penelitian.

\section{REFERENCES}

[1] Fricles Ariwisanto Sianturi, "PENERAPAN METODE SIMPLE ADDITIVE WEIGHTING (SAW) DALAM SISTEM PENDUKUNG KEPUTUSAN PENENTUAN SHIFT PEGAWAI (STUDI KASUS: RS.BHAYANGKARA TK.II MEDAN," J. Inf. Komput. Log., vol. I, no. 2, pp. 43-47, 2019.

[2] H. A. Yudha, B. Yuwono, and F. R. Kodong, "Sistem Pendukung Keputusan Menggunakan Metode Promethee (Studi Kasus : Stasiun Pengisian Bahan Bakar Umum)," Telematika, vol. 7, no. 1, 2015, doi: 10.31315/telematika.v8i1.444.

[3] D. F. Sudrajat and D. W. I. Novirani, "Usulan Penentuan Rangking Supplier Bahan Baku Baja dengan Metode Promethee ( Studi Kasus PT . PINDAD PERSERO ) *," vol. 1, no. 1, pp. 204-215, 2013.

[4] R. Watrianthos, K. Kusmanto, E. F. S. Simanjorang, M. Syaifullah, and I. R. Munthe, "Penerapan Metode Promethee Sebagai Sistem Pendukung Keputusan Pemeringkatan Siswa,” J. Media Inform. Budidarma, vol. 3, no. 4, p. 381, 2019 doi: $10.30865 / \mathrm{mib} . v 3 i 4.1546$.

[5] Basri, "METODE WEIGHTD PRODUCT (WP) DALAM SISTEM PENDUKUNG KEPUTUSAN PENERIMAAN BEASISWA PRESTASI," J. INSYPRO (Information Syst. Process., 2017, doi: https://doi.org/10.24252/insypro.v2i1.2474.g2610.

[6] R. Rumapea, P. Maleahki, S. Negara, and D. R. S. P. "Sistem Pendukung Keputusan Guru Beprestasi Berbasis Web di SMA Swasta Yapim Sibiru-Biru," vol. 2, no. 1, pp. 23-28, 2020.

[7] P. Soepomo, "Sistem Pendukung Keputusan Seleksi Calon Karyawan Dengan Metode Promethee Studi Kasus Pamella Group Yogyakarta," J. Sarj. Tek. Inform., vol. 2, no. 1, pp. 264-278, 2014, doi: 10.12928/jstie.v2i1.2633.

[8] T. Juninda, E. Andri, U. Kahirunnisa, N. Kurniawati, and M. Mustakim, "Penerapan Metode Promethee Untuk Pendukung Keputusan Pemilihan Smartphone Terbaik," J. Ilm. Rekayasa dan Manaj. Sist. Inf., vol. 5, no. 2, p. 224, 2019, doi: $10.24014 /$ rmsi.v5i2.7677.

[9] S. S. Helma et al., "Penerapan Metode SMARTER untuk Penentuan Hasil Open Recruitment Anggota Puzzle Research Data Technology ( Predatech )," Sntiki, 2019.

[10] G. Ade and Okfalisa, "Sistem Pendukung Keputusan Untuk Produk Asuransi Jiwa Bagi Nasabah Menggunakan Metode SMARTER," J. Sains, Teknol. dan Ind., 2014.

[11] G. Gusrianty, D. Oktarina, and W. J. Kurniawan, "Sistem Pendukung Keputusan Dengan Metode Promethee Untuk Menentukan Kepuasan Pelanggan Penjualan Sepeda Motor Bekas,” Sistemasi, vol. 8, no. 1. p. 62, 2019, doi: 10.32520/stmsi.v8i1.419.

[12] D. C. Windya Shagara, Indah Fitri Astuti, "Sistem Pendukung Keputusan Penentuan Wilayah Migrasi Pelanggan Internet Menggunakan Metode Promethee (Studi Kasus: PT Telkom Indonesia Samarinda).” pp. 1858-4853, 2019.

[13] D. Haryanti, H. Nasution, and A. S. Sukamto, "Sistem Pendukung Keputusan Seleksi Penerimaan Mahasiswa Pengganti Beasiswa Penuh Bidikmisi Universitas Tanjungpura Dengan Menerapkan Metode SMARTER,” J. Sist. dan Teknol. Inf., 2016. 
JURNAL MEDIA INFORMATIKA BUDIDARMA

Volume 5, Nomor 2, April 2021, Page 739-745

ISSN 2614-5278 (media cetak), ISSN 2548-8368 (media online)

Available Online at https://ejurnal.stmik-budidarma.ac.id/index.php/mib DOI $10.30865 /$ mib.v5i2.2948

[14] T. MIv et al., Think Smarter \{critical thinking to improve probem solving and decision making skills \}. 2015.

[15] N. R. Muntiari, S. Sunardi, and A. Fadlil, "Sistem Penentuan Penginapan dengan Metode Promethee," J. Ilm. Mandala Educ., vol. 6, no. 1, pp. 12-19, 2020, doi: 10.36312/jime.v6i1.1098.

[16] I. Taufik, U. Syaripudin, and J. Jumadi, "Implementasi Metode Promethee Untuk Menentukan Penerima Beasiswa," $J$. Istek, vol. 10, no. 1, 2017.

[17] IRLANE MAIA DE OLIVEIRA, "SISTEM PENDUKUNG KEPUTUSAN PEMILIHAN JENIS KAMERA CCTV MENGGUNAKAN METODE PROMETHEE,” pp. 1-14, 2017. 